\title{
Electrophysiology of the Hippocampal and Amygdaloid Projections to the Nucleus Accumbens of the Rat: Convergence, Segregation, and Interaction of Inputs
}

\author{
Antonius B. Mulder, Martijn Gijsberti Hodenpijl, and Fernando H. Lopes da Silva \\ Graduate School for Neurosciences, Institute of Neurobiology, Faculty of Biology, University of Amsterdam, \\ 1098 SM Amsterdam, The Netherlands
}

The nucleus accumbens (Nacb) receives inputs from hippocampus and amygdala but it is still unclear how these inputs are functionally organized and may interact. The interplay between these input pathways was examined using electrophysiological tools in the rat, in vivo, under halothane anesthesia. After fornix/fimbria stimulation (Fo/Fi, subicular projection fibers to the Nacb), mono- and polysynaptically driven single units were recorded in the medial shell/core regions of the Nacb and in the ventromedial caudate putamen. Monosynaptically driven neurons by basolateral amygdala (BLA) stimulation were found in the medial shell/core and in the ventrolateral shell/core regions. In the areas of convergence (medial shell/core), paired activation of BLA followed by that of $\mathrm{Fo} / \mathrm{Fi}$ resulted in an enhancement of the Fo/Fi response, whereas stimulation in the reverse order, Fo/Fi followed by BLA, led to a depression of the
$B L A$ response. In addition to these patterns of interactions, the tetanization of the Fo/Fi to Nacb pathway caused a homosynaptic decremental (long-term) potentiation in the Nacb, accompanied by a heterosynaptic (long-term) depression of the nontetanized BLA to Nacb pathway. We postulate that the hippocampal inputs may close a "gate" for the amygdala inputs, whereas the gate is opened for the hippocampus inputs by previous amygdalar activity. These opposite effects on the Nacb neuronal populations should be taken into account when interpreting behavioral phenomena, particularly with respect to the contrasting effects of the amygdala and the hippocampus in locomotion and place learning.

Key words: nucleus accumbens; basolateral amygdala; hippocampus; limbic system; homosynaptic LTP; heterosynaptic LTD; paired-pulse facilitation; single unit; rat
The nucleus accumbens (Nacb) forms a limbic-motor interface as originally proposed by Heimer and Wilson (1975) and Mogenson et al. (1980). Indeed, the Nacb receives input from various limbic structures, including the hippocampal formation (DeFrance et al., 1980, 1985; Lopes da Silva et al., 1984; Yang and Mogenson, 1984, 1985; Christie et al., 1987; Groenewegen et al., 1987) and the basolateral amygdala (BLA) (Krettek and Price, 1978; Yim and Mogenson, 1982, 1986, 1989; McDonald, 1991; Shinonaga et al., 1994; Kirouac and Ganguly, 1995; Wright et al., 1996), and projects to areas involved in motor programming, such as the pallidum (Nauta et al., 1978; Mogenson and Nielsen, 1984; Yang and Mogenson, 1985; Napier et al., 1995), the midbrain extrapyramidal area (Berendse et al., 1992), and the dopaminergic cell groups of the substantia nigra and ventral tegmental area (Nauta et al., 1978; Heimer et al., 1991). The two main limbic input structures of the Nacb, the amygdala and the hippocampal formation, can be assigned to distinct behaviors. The amygdala forms a link between sensory systems and structures involved in emotional behavior (Davies, 1992; LeDoux, 1993; Adolphs et al., 1995), whereas the hippocampal formation is important in memory tasks particularly involving spatial cues (Morris et al., 1982; Zola-Morgan et al., 1986, 1989, 1991; Alvarez et al., 1995).

\footnotetext{
Received Sept. 2, 1997; revised April 17, 1998; accepted April 21, 1998.

This work was supported by the foundation for Medical Research (MEDIGON, Grant 900-550-093) of the Dutch Organization for Scientific Research (NWO). We thank Professor Dr. H. J. Groenewegen for his valuable comments on this manuscript.

Correspondence should be addressed to A. B. Mulder, Netherlands Institute for Brain Research, Meibergdreef 33, 1105 AZ Amsterdam ZO, The Netherlands. Copyright (C) 1998 Society for Neuroscience $0270-6474 / 98 / 185095-08 \$ 05.00 / 0$
}

Taken separately, the hippocampal and amygdaloid inputs to the Nacb have been anatomically mapped and electrophysiologically characterized. However, as yet, little is known about how hippocampal and amygdalar information inputs interact to program behavioral acts. Nevertheless, we know that locomotion is affected differently by manipulations of amygdalar or hippocampal circuits. Injections of NMDA in the amygdala lead to an attenuation of locomotion (Yim and Mogenson, 1989), whereas NMDA injected in the hippocampus produces an enhancement (Mogenson and Nielsen, 1984). Both of these effects are completely antagonized by intra-accumbens administration of an AMPA/kainate antagonist or by dopamine (Yim and Mogenson, 1989). How such contrasting effects can be accounted for at the physiological level is unclear because electrical stimulation of the BLA or the hippocampal formation produces apparently identical EPSP-IPSP sequences in cells of the Nacb (Yim and Mogenson, 1986; Pennartz and Kitai, 1991). Interactions among excitatory inputs from prefrontal cortex and hippocampus to the Nacb were studied using in vivo intracellular recordings by O'Donnell and Grace (1995), showing that hippocampal input is necessary for Nacb neurons to enter an active state. Also, on a small number of Nacb cells, Finch (1996) has shown convergence of various limbic inputs.

To better understand how amygdalar and hippocampal inputs can modulate the behavior of Nacb neurons in distinct ways, we mapped the functional localization of the Nacb neurons with respect to these two main inputs by stimulating, in vivo in the rat, the BLA and the Fo/Fi. The cellular responses were recorded, and the patterns of convergence and segregation of the two inputs were studied. In the areas of convergence, the interactions be- 
tween the two inputs were examined using protocols to induce paired-pulse and long-term potentiation/depression.

Parts of this work have been published previously in preliminary form (Mulder et al., 1995a; Mulder and Lopes da Silva, 1996).

\section{MATERIALS AND METHODS}

Basic surgery and placement of electrodes. Male Wistar rats $(n=18 ; \sim 200$ gm) were initially anesthetized in a chamber (3\% halothane in $\mathrm{O}_{2}$ and $\mathrm{N}_{2} \mathrm{O}$ ) after which the trachea was intubated. Thereafter, the rats were artificially respirated with a mixture of $0.9 \%$ halothane in $\mathrm{O}_{2}$ and $\mathrm{N}_{2} \mathrm{O}$ and mounted in a stereotaxic frame. The skull was exposed, and burr holes were made according to the coordinates of the atlas of Pellegrino et al. (1981). All electrodes were zeroed on the interaural line, midline, and cortical surface. Stimulation electrodes (Trimel-coated stainless steel, $60 \mu \mathrm{m}$ ) were placed in the BLA [anterior (A), $5.0 \mathrm{~mm}$; lateral (L), $5.0 \mathrm{~mm}$; ventral $(\mathrm{V}), 7.5 \mathrm{~mm})$ and the $\mathrm{Fo} / \mathrm{Fi}(\mathrm{A}, 5.5 \mathrm{~mm}$;, $1.5 \mathrm{~mm}$; V, $3.5 \mathrm{~mm}$ ). Single unit activity and field potentials, evoked by Fo/Fi and/or BLA stimulation, were recorded in the Nacb (A, 8.5-9.5 mm; L, 1.0-2.5 $\mathrm{mm} ; \mathrm{V}, 5.5-8.0 \mathrm{~mm})$, using glass microelectrodes $(10-30 \mathrm{M} \Omega$, filled with $2 \%$ pontamine sky blue in acetate buffer, $2 \mathrm{~m}, \mathrm{pH} 8.2$ ). In every experiment, several penetrations of the Nacb were systematically performed from the dorsal to the ventral border at various rostrocaudal and mediolateral coordinates.

Stimulation and data acquisition. Standard bipolar Fo/Fi and/or BLA stimulation consisted typically of two identical $0.2 \mathrm{msec}$ paired pulses, at an interval of $100 \mathrm{msec}$, with intensities ranging from 100 to $700 \mu \mathrm{A}$ and delivered at a low repetition rate (once every $7.5 \mathrm{sec}$ ). The first stimulus of the pair is called the "conditioning" $(\mathrm{C})$ pulse, and the second is called the "test" (T) pulse. "Evoked field potentials" (EFPs) were amplified (CyberAmp, Axon Instruments, Foster City, CA) and digitized by way of a CED 1401 interface (Cambridge Electronic Design, Cambridge, UK) that was connected to an IBM-PC. Standard sampling rate was set to 5000 samples/sec, and EFPs were averaged $(n=16)$ and stored on hard disk. Single-unit activity was bandpass-filtered $(500-3500 \mathrm{~Hz})$, and individual single-unit action potentials were separated from noise using a window discriminator and sampled on-line by a computer connected to a CED 1401 interface. Peristimulus time histograms were constructed on-line. The evoked field potentials and the single-unit activity on stimulation of the $\mathrm{Fo} / \mathrm{Fi}$, and/or BLA, were examined in relation to the location within the Nacb.

Paired-pulse facilitation and long-term potentiation. The field potentials evoked by $\mathrm{Fo} / \mathrm{Fi}$ and BLA stimulation at different intensities (inputoutput curves) were measured separately. In this way, the stimulation intensity at which the amplitudes of the corresponding EFPs saturated was determined. In general, an intensity corresponding to $50 \%$ of the saturation level was chosen for the test stimulus. For quantification, the amplitudes of the rising and decaying flanks of the synaptic field components of the individual EFPs were calculated and averaged. The firing probability of single units was determined; it was defined as the percentage of stimuli that evoked one action potential at a certain stimulus intensity. Therefore, a firing probability of $50 \%$ relates to a stimulus intensity that has a $50 \%$ chance of eliciting one action potential.

Paired-pulse facilitation (PPF) of the responses of the Nacb was examined, for both pathways separately, at different interstimulus intervals at the intensity indicated above. Subsequently, the interactions between $\mathrm{Fo} / \mathrm{Fi}$ and $\mathrm{BLA}$ stimulation were investigated by applying, at different intervals, the conditioning stimulus to the $\mathrm{Fo} / \mathrm{Fi}$ and the test stimulus to the BLA or vice versa.

Long-term potentiation (LTP) was elicited in the Nacb by a tetanic stimulation of the Fo/Fi fibers. This consisted of 100 equidistant pulses $(50 \mathrm{~Hz}, 2 \mathrm{sec})$ given near saturation intensity. To establish baseline controls, EFPs were recorded separately in the Nacb after Fo/Fi and BLA stimulation, for $15 \mathrm{~min}$, before a single tetanic stimulation was applied to the Fo/Fi pathway. During the 90 min after the tetanus, EFPs were recorded in the tetanized pathway (Fo/Fi to Nacb) and in the nontetanized pathway (BLA to Nacb), in an alternating sequence. The response of the Nacb during the tetanus and 1 min after tetanus was monitored continuously to check for the possible occurrence of afterdischarges. The rats in which after-discharges were encountered were not used in the LTP study.

Histological verification. After all data were recorded, the electrode placements were marked and the brains were removed. After immersion fixation (4\% paraformaldehyde, $0.05 \%$ glutaraldehyde in phosphate buffer), transverse sections $(40 \mu \mathrm{m})$ were cut on a freezing microtome, and a
Nissl staining was performed to verify the electrode placements histologically. These placements were subsequently transferred to standard levels of the Nacb taken from the atlas of Paxinos and Watson (1996). In these sections, the representative shell/core border based on differential calbindin-protein immunoreactivity (Jongen-Rêlo et al., 1994) was indicated (see Fig. 2).

Experimental design and statistical evaluation. Only results obtained in animals in which all three electrode placements were correct and in which $\mathrm{Fo} / \mathrm{Fi}$ and BLA stimulation elicited single-unit responses were included. The cell searching procedure consisted of a double-pulse protocol giving one pulse to BLA and one to Fo/Fi (or vice versa), with a standard interpulse interval of $100 \mathrm{msec}$ delivered every $7.5 \mathrm{sec}$. The number of BLA stimulations matched the number of Fo/Fi stimulations in the individual rats. Not more than three electrode tracks in the Nacb per rat were performed. Usually these tracks were at different mediolateral coordinates. Sites at which paired-pulse interaction $(\mathrm{BLA}-\mathrm{Fo} / \mathrm{Fi}$ or vice versa) protocols were delivered were always marked. The deepest recording site of all the individual electrode tracks was marked. After LTP-inducing protocols, the recording site was marked and the rat was perfused. All values are given as mean \pm SEM. The results were tested using the Student's $t$ test for paired comparisons $\left({ }^{*}=p<0.05,{ }^{*}=p<\right.$ $0.01, * * *=p<0.001)$, unless stated otherwise.

\section{RESULTS \\ Evoked field potentials}

In the Nacb, stimulation of the Fo/Fi caused characteristic field potentials (Fig. 1), which have been described previously (Boeijinga et al., 1993; Mulder et al., 1997). In short, the EFP consisted of two positive synaptic components: the latency of the first one was $10 \mathrm{msec}$ on average (P10, monosynaptically driven), and the latency of the second one was $25 \mathrm{msec}$ (P25, polysynaptically driven) (Fig. 1A1,2,3). In the entire Nacb, the peaks of the EFPs were of similar amplitude and latency.

On BLA stimulation (Fig. 1), the characteristic EFP consisted of one clear negativity, with an average latency of $16 \mathrm{msec}$ in the medial part of the Nacb (Fig. 1B1,2,3) and significantly longer latencies in the ventrolateral Nacb (Fig. 1C1,2,3).

\section{Single unit activity}

In total 154 single units were recorded in the Nacb driven by Fo/Fi stimulation.

The Nacb units driven by $\mathrm{Fo} / \mathrm{Fi}$ stimulation were located mainly in the medial shell/core regions (Fig. 2, bottom panels). In the lateral shell and the ventral and lateral core, no Fo/Fi-driven cells were encountered. Also $\mathrm{Fo} / \mathrm{Fi}$ responding units were recorded in the ventromedial part of the caudate-putamen lining the lateral ventricle. The occurrence of action potentials always coincided with the rising phase or the peak of the positive components of the EFP, e.g., either the P10 or the P25 (Fig. 1). Within the P10 and P25 ranges, Nacb neurons responded with one single action potential (no bursts) on a single stimulus. The nature of the response, either monosynaptic or polysynaptic, was determined by applying double pulses with short interpulse intervals. The following criterion was used (based on Laroche et al., 1990; Finch et al., 1995; Finch, 1996): firing activity able to follow both pulses given at a $4 \mathrm{msec}$ pulse interval and failing to respond to the second pulse when the interpulse interval was set to 2.5 msec was considered to be monosynaptic, whereas firing activity already failing at interpulse intervals of 10-20 msec was labeled polysynaptic. In all areas within the Nacb mentioned above, monosynaptic responses $(n=111 ; 9.5 \pm 0.1 \mathrm{msec}$ on average) were found, whereas the polysynaptic single unit activity $(n=74$; $21.0 \pm 0.2 \mathrm{msec}$ on average) was concentrated mainly in the mid-rostrocaudal Nacb (Fig. 2, bottom panels). Thirty-one units presented both monosynaptic and polysynaptic responses. Figure 3 shows the spike latency distribution of the units of the Nacb 

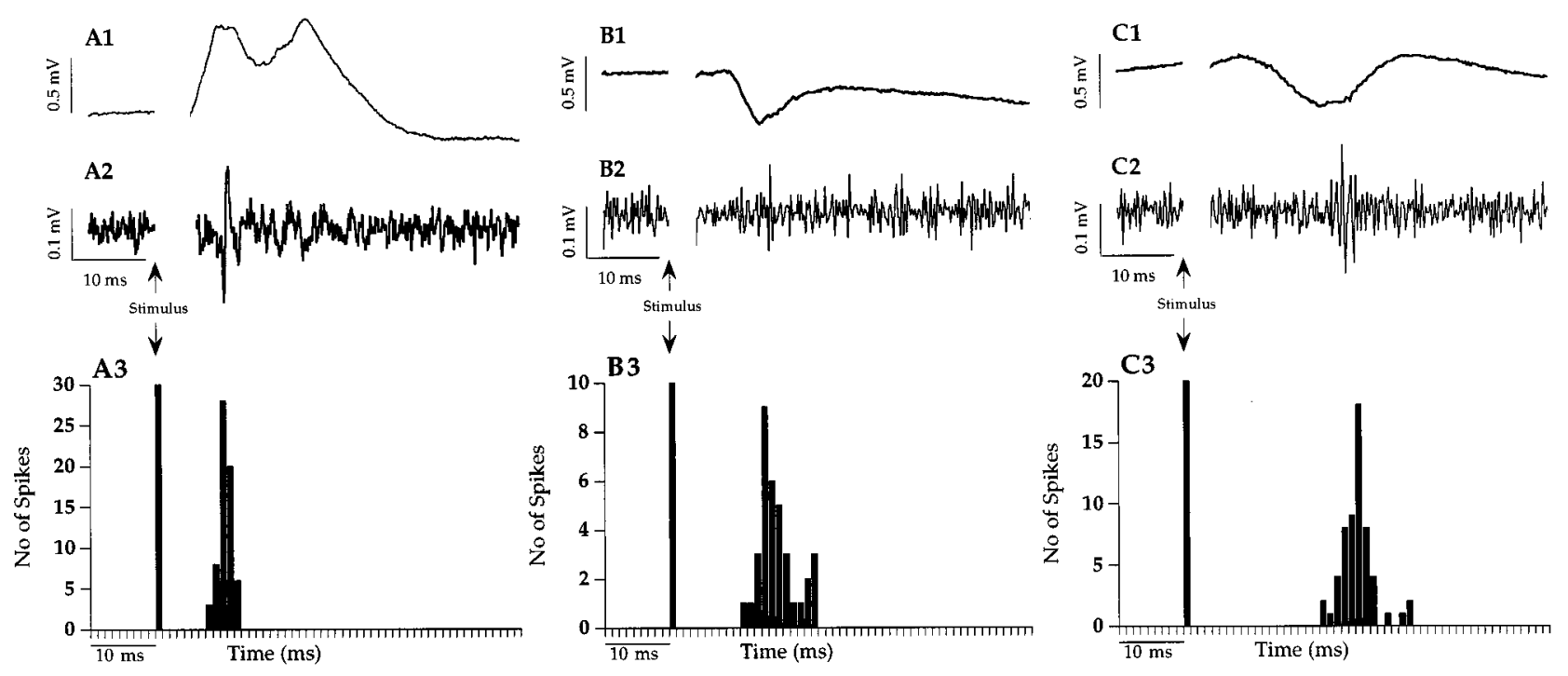

Figure 1. Evoked responses recorded in the Nacb. Recording in the medial shell and medial core regions of the Nacb resulted in evoked field potentials with positive peak latencies of $\sim 10$ and $22 \mathrm{msec}$ to Fo/Fi stimulation $(A 1)$ and negative peak latencies of $\sim 16$ msec to BLA stimulation (B1), whereas in the ventrolateral shell and core regions, on BLA stimulation, EFPs with longer latencies were recorded $(C 1)$. In $A 2$, $B 2$, and $C 2$, single traces (bandpass-filtered) show action potentials that coincide with the positive peaks of the Fo/Fi-induced EFP and the negative peaks of the EFP to BLA stimulation. Peristimulus time histograms of the single unit activity to $\mathrm{Fo} / \mathrm{Fi}$ and BLA stimulation presented in $A 3, B 3$, and $C 3$ were constructed (64 sweeps). Clearly visible is the peak latency at $9 \mathrm{msec}$ to $\mathrm{Fo} / \mathrm{Fi}$ stimulation $(A 3)$ in the medial shell/core and the $15 \mathrm{msec}(B 3)$ and $23 \mathrm{msec}(C 3)$ peak latency in medial shell/core and ventrolateral shell/core, respectively, to BLA stimulation. The second peak visible in $B 3$ after $21 \mathrm{msec}$ is attributable to the occurrence of an occasional burst of two action potentials.

driven by Fo/Fi stimulation in which the two distinct populations of monosynaptic and polysynaptic activation are clearly visible. The response latency of an individual neuron was based on at least 16 trials. The action potential latencies of the monosynaptic responses in the rostral Nacb were significantly longer compared with the mid-rostrocaudal and caudal regions, whereas in the mid-rostrocaudal area, medial core latencies are significant longer than in the medial shell (Table 1). Therefore, the axis of increasing response latencies of single units responding to Fo/Fi stimulation runs from the caudomedial to rostrolateral Nacb.

Only a few single units were found in the most medial parts of the shell and the rostrolateral shell. This may be attributable to a bias in the electrophysiological protocol: the stimulation electrodes were located in the intermediate mediolateral part of the $\mathrm{Fo} / \mathrm{Fi}$ fibers for excitation of a maximal number of fibers. In this way, fibers in the (dorso)medial and lateral portions of the $\mathrm{Fo} / \mathrm{Fi}$, which reach the caudomedial and rostrolateral parts of the Nacb (Groenewegen et al., 1987), respectively, may have been activated suboptimally by our stimulations.

On stimulation of the BLA, a total of 68 single units were studied in the Nacb. Single units were recorded in the medial shell/core regions and in the ventrolateral Nacb in both shell and core areas (Fig. 2, bottom panels). Action potentials occurred in relation to the negative field potential (Fig. 1) and could be classified as monosynaptic. In general, cells responded with a single spike on one stimulus, although occasionally bursts of two or three action potentials were recorded, especially on large stimulation intensities (Fig. 1B3, PSTHs). Figure 3 shows the spike latency distribution of the BLA-driven single units. A population of single units firing with latencies shorter than 20 msec was found in the medial shell/core regions, whereas single cells with longer latencies were located exclusively in the ventrolateral Nacb in both shell and core (Table 1). Also, on BLA stimulation, a few single units $(n=3$; latency $14 \pm 1 \mathrm{msec})$ in the tuberculum olfactorium were recorded.

\section{Convergence and segregation of inputs within the nucleus accumbens}

A convergence of inputs from the $\mathrm{Fo} / \mathrm{Fi}$ and BLA was found in 34 cells, mainly in the medial shell but also in the medial core regions (Fig. 2, bottom panels) and rarely in the dorsomedial part of the shell and not in the ventrolateral shell and the ventral core regions or in the ventromedial part of the caudate putamen. In the dorsomedial shell of the Nacb and the ventromedial part of the caudate putamen, only $\mathrm{Fo} / \mathrm{Fi}$ driven cells were encountered, whereas in the ventrolateral areas of the Nacb in both shell and core only single units driven by BLA stimulation were found. No differences in response latencies between cells that are activated only by $\mathrm{Fo} / \mathrm{Fi}$ and cells that also received BLA inputs were found (Table 1). The BLA-driven cells in the medial shell of the caudal area, which presented convergence of inputs, displayed significantly shorter latencies than those in the medial shell of the mid-rostrocaudal area (Table 1). The single units recorded in the ventrolateral areas, which showed no convergence, were classified as long-latency, and at least in the mid-rostrocaudal area were significantly longer than the medial shell and core latencies.

\section{Interaction of hippocampal and amygdaloid inputs in the nucleus accumbens}

In the areas of convergence of the monosynaptically driven $\mathrm{Fo} / \mathrm{Fi}$ and BLA activity, the interaction between both inputs was studied.

To measure PPF, the firing probabilities of single units were determined. In the 10 cases studied, PPF could be readily induced in the Fo/Fi to Nacb pathway as described previously (Boeijinga et al., 1990) and also in the BLA to Nacb pathway, as shown in the example of Figure 4. However, when the test stimulus was given to the BLA preceded by the conditioning stimulus to the $\mathrm{Fo} / \mathrm{Fi}$ $(\mathrm{Fo} / \mathrm{Fi}+\mathrm{BLA})$, the firing probability was markedly lower than after a single BLA stimulation (Fig. 4A). This was observed in all neurons tested $(n=10)$, recorded in the area of convergence. Application of the conditioning pulse to the BLA and the test 
Bregma $+2.20 \mathrm{~mm}$

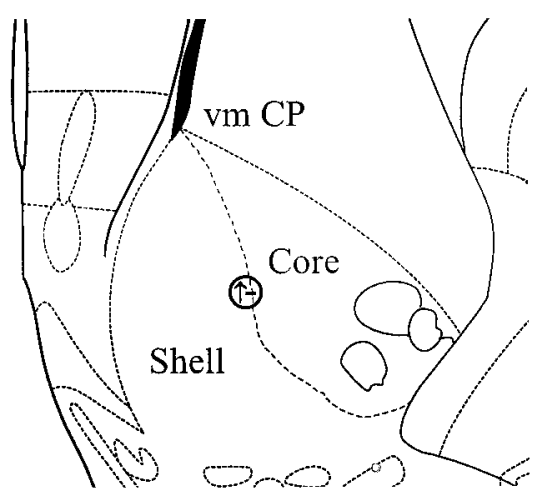

Bregma $+1.60 \mathrm{~mm}$
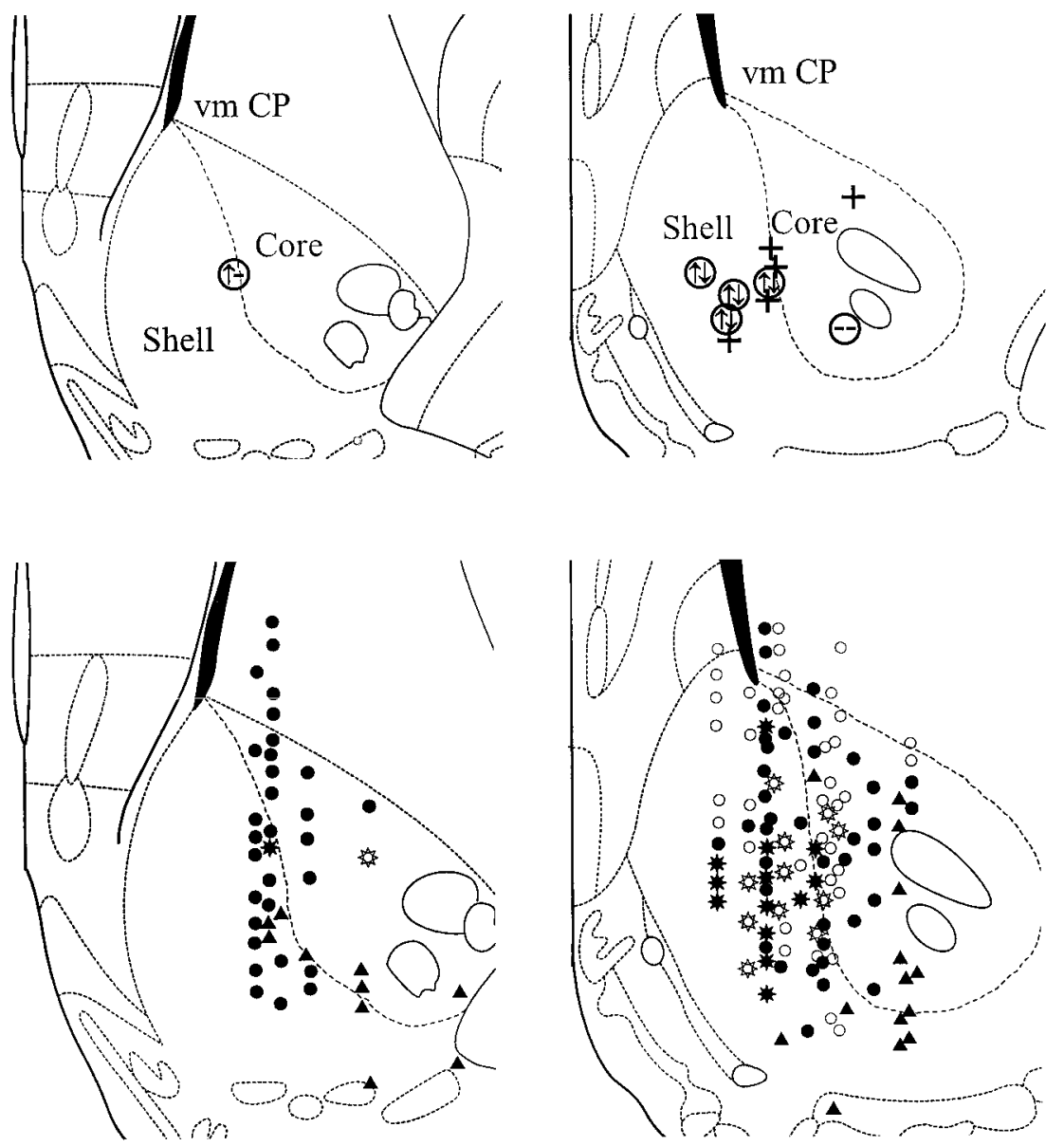

Bregma $+1.2 \mathrm{~mm}$
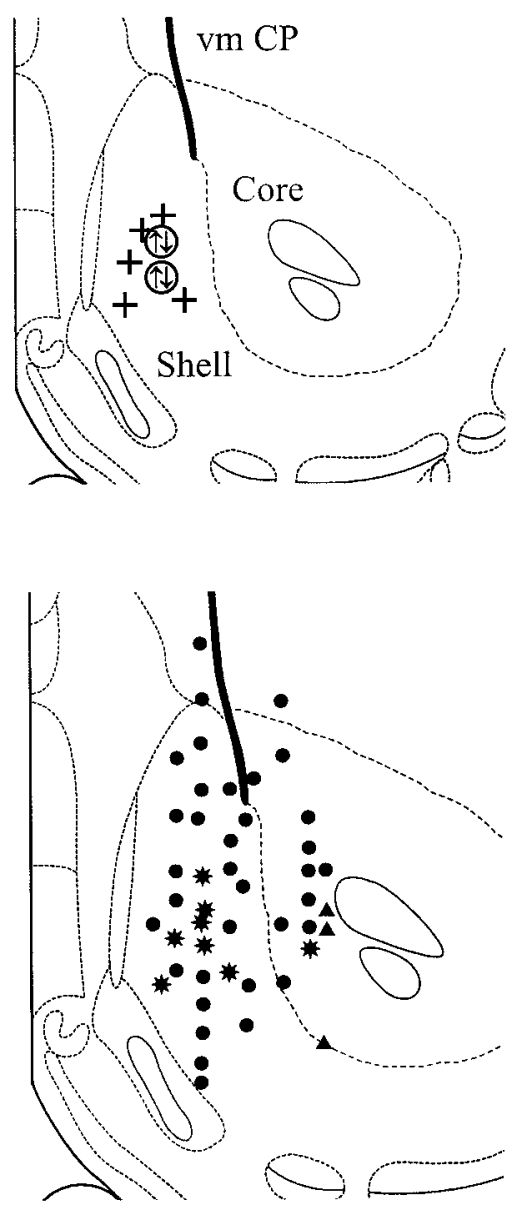

Figure 2. Distribution of single-unit activity within the Nacb to Fo/Fi and BLA stimulation. The transverse sections are modified from the atlas of Paxinos and Watson (1996). Three sections from rostral to caudal Nacb are presented. Top panels, The boundary between shell and core region (short dashes) was based on Jongen-Rêlo et al. (1994) in which calbindin protein staining was used. The circles represent locations where LTP was elicited in the Nacb to Fo/Fi tetanization. Within the circles, the left symbol relates to the Fo/Fi to Nacb pathway, whereas the right symbol is for the BLA to Nacb pathway. $\uparrow$, Potentiation; $\downarrow$, depression; -, no effect. + indicates the location where PPF was studied. Bottom panels, Monosynaptically $(\bullet)$ and polysynaptically $(\bigcirc)$ driven single units to Fo/Fi stimulation and monosynaptically driven single units to BLA stimulation $(\boldsymbol{\Delta})$ are presented. Single units presenting mono- and polysynaptic responses to Fo/Fi stimulation are also indicated by filled circles. Single units responding to both Fo/Fi and BLA stimulation are indicated by star-shaped symbols ( filled, monosynaptically driven by Fo/Fi; open, polysynaptically driven by Fo/Fi). Only Fo/Fi-driven units were found in the dorsal shell and the ventromedial caudate putamen $(\mathrm{vm} \mathrm{CP})$, whereas only BLA-driven activity was recorded in the ventrolateral part of the Nacb in both shell and core regions. Single units responding to both stimuli were recorded in the medial shell and medial core regions.

pulse to the $\mathrm{Fo} / \mathrm{Fi}(\mathrm{BLA}+\mathrm{Fo} / \mathrm{Fi})$ resulted in an increased firing probability of the $\mathrm{Fo} / \mathrm{Fi}$ response compared with one single $\mathrm{Fo} / \mathrm{Fi}$ stimulation, but the facilitation was less than in the case of paired Fo/Fi stimulation (Fig. 4B). Table 2 gives a summary of the PPF data. Although in general the stimulation intensities were not varied systematically, we could observe that in an individual cell in which BLA (50\% saturation intensity) response was attenuated after previous Fo/Fi stimulation (50\% saturation intensity), activity was still decreased when the $\mathrm{Fo} / \mathrm{Fi}$ was stimulated with an intensity range from 15 to $85 \%$ of the saturation intensity.

In eight rats, we examined whether long-term potentiation of the Fo/Fi to Nacb pathway would affect the response to BLA stimulation. In seven rats this led to the characteristic accumbens decremental LTP (Mulder et al., 1997), consisting of an initial amplitude increase of $\sim 160 \%$ followed by a decremental form of LTP lasting $\sim 60 \mathrm{~min}$. Unexpectedly, in six rats we found that during the period of potentiation of the Fo/ Fi to Nacb pathway, the nontetanized BLA to Nacb pathway showed long-term depression (LTD). In the rat in which the BLA to Nacb response was not affected by LTP in the $\mathrm{Fo} / \mathrm{Fi}$ to $\mathrm{Nacb}$ pathway, the recording electrode was located in an area where very little convergence of the two inputs was observed (Fig. 2). The time courses of the LTP of the Fo/Fi to Nacb pathway and the LTD of the BLA to Nacb pathway for the six rats are shown in Figure 5.

\section{DISCUSSION}

The primary result of this study is that convergence and interactions of BLA and hippocampal inputs were found in the medial shell/core regions of the Nacb. In the dorsomedial shell of the Nacb and the ventromedial caudate-putamen, only Fo/Fi-driven cells were encountered, whereas in the ventrolateral shell/core only single units driven by BLA stimulation were found. Second, within the region of convergence, activation of a single pathway before the other results in a modulation of the latter, either an 

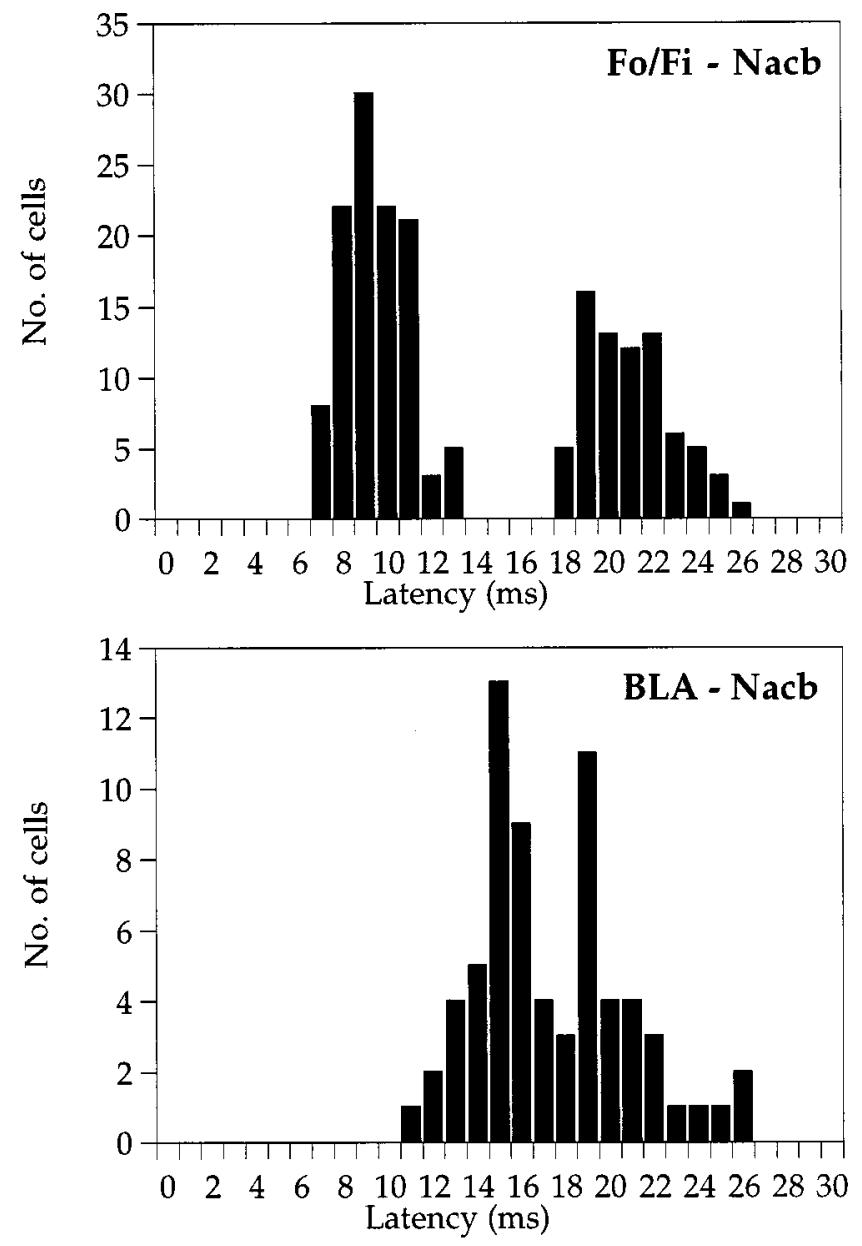

Figure 3. Distribution of the latencies of Nacb single units driven by $\mathrm{Fo} / \mathrm{Fi}$ and/or by BLA stimulation. Clearly visible are the two distinct latencies at which $\mathrm{Fo} / \mathrm{Fi}$-driven neurons could be found that correspond to the two peaks of the evoked field potential P10 and P25. The BLA-driven units display latencies with peaks at 15 and $19 \mathrm{msec}$. These single units were all found in the medial shell and medial core regions of the Nacb. Neurons displaying latencies of $20 \mathrm{msec}$ and longer to BLA stimulation were found exclusively in the ventrolateral parts of the Nacb in both shell and core.

enhancement in the case in which the conditioning stimulus is applied to the BLA and the test to the $\mathrm{Fo} / \mathrm{Fi}$, or a depression in the opposite case. Third, decremental LTP of the Fo/Fi to Nacb pathway is accompanied by LTD of the nontetanized BLA to Nacb pathway in regions of the Nacb where convergence was encountered.

\section{Termination patterns of amygdalar and hippocampal afferents in the accumbens}

The area of convergence corresponds in general to that described in previous anatomical (Groenewegen et al., 1987; Shinonaga et al., 1994; Kirouac and Ganguly, 1995; Wright et al., 1996) and electrophysiological investigations (DeFrance et al., 1980, 1985; Yim and Mogenson, 1982, 1986, 1989; Yang and Mogenson, 1984, 1985; Calloway et al., 1991) in which, however, the two pathways were studied separately.

The distribution of latencies of single units responding to $\mathrm{Fo} / \mathrm{Fi}$, the shortest in the caudal dorsomedial area of the Nacb that increased in the rostral ventrolateral direction, is consistent with the fact that the Fo/Fi fibers enter the Nacb from a caudal

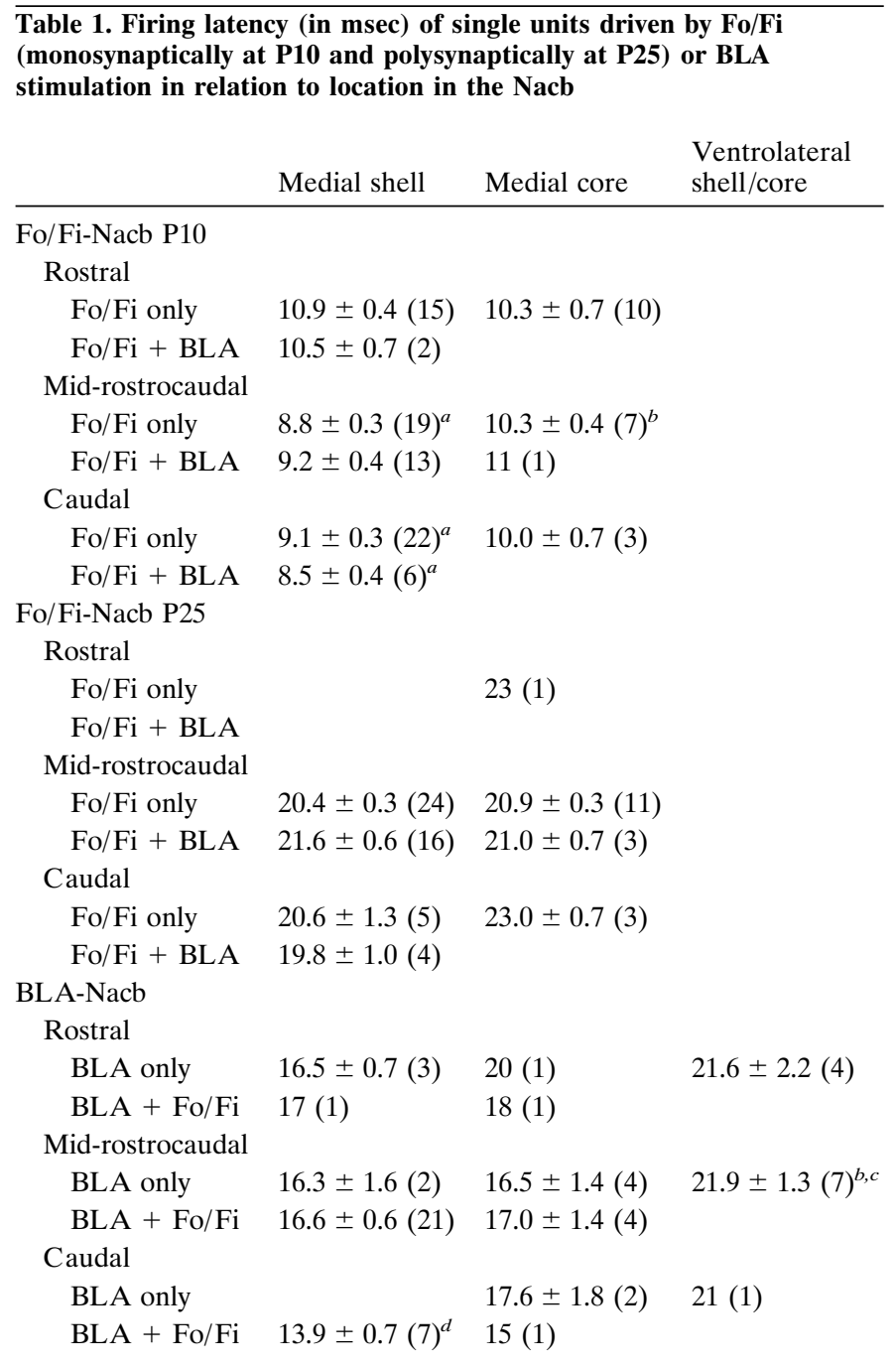

The number of cells at the corresponding location is given between brackets. $\mathrm{Fo} / \mathrm{Fi}$ and BLA indicates only Nacb cells that are activated by either BLA or $\mathrm{Fo} / \mathrm{Fi}$ stimulation. $\mathrm{BLA}+\mathrm{Fo} / \mathrm{Fi}$ or $\mathrm{Fo} / \mathrm{Fi}+\mathrm{BLA}$ indicates cells that are activated by both stimulations.

${ }^{a}$ Student's $t$ test; significantly different from corresponding rostral value.

${ }^{b}$ Student's $t$ test; significantly different from corresponding medial shell value within the area.

${ }^{c}$ Student's $t$ test; significantly different from corresponding medial core value within the area.

${ }^{d}$ Student's $t$ test; significantly different from corresponding mid rostrocaudal value.

dorsomedial position, fanning out in rostral and lateral directions (Groenewegen et al., 1987).

With respect to the distribution of the electrophysiological responses to stimulation of the BLA, there was a good correspondence with the terminal fields of the fibers arising from different subdivisions of the basal nuclei of the amygdala, as shown by tracing studies (Wright et al., 1996). Nacb neurons responding to BLA stimulation display relatively short latencies in the medial shell/core regions ( $\sim 15$ and $19 \mathrm{msec})$ and longer latencies (20-26 $\mathrm{msec}$ ) in the ventrolateral shell and lateral core. These are in line with earlier reports, although no relationships between latencies and locations in the Nacb were reported (Yim and Mogenson, 1982, 1986, 1989; O’Donnell and Grace, 1995). A possible anatomical basis for these differences in latencies is that the fibers originating in the basal nuclei of the amygdala course toward the Nacb by two major pathways. Fibers originating in the rostral 

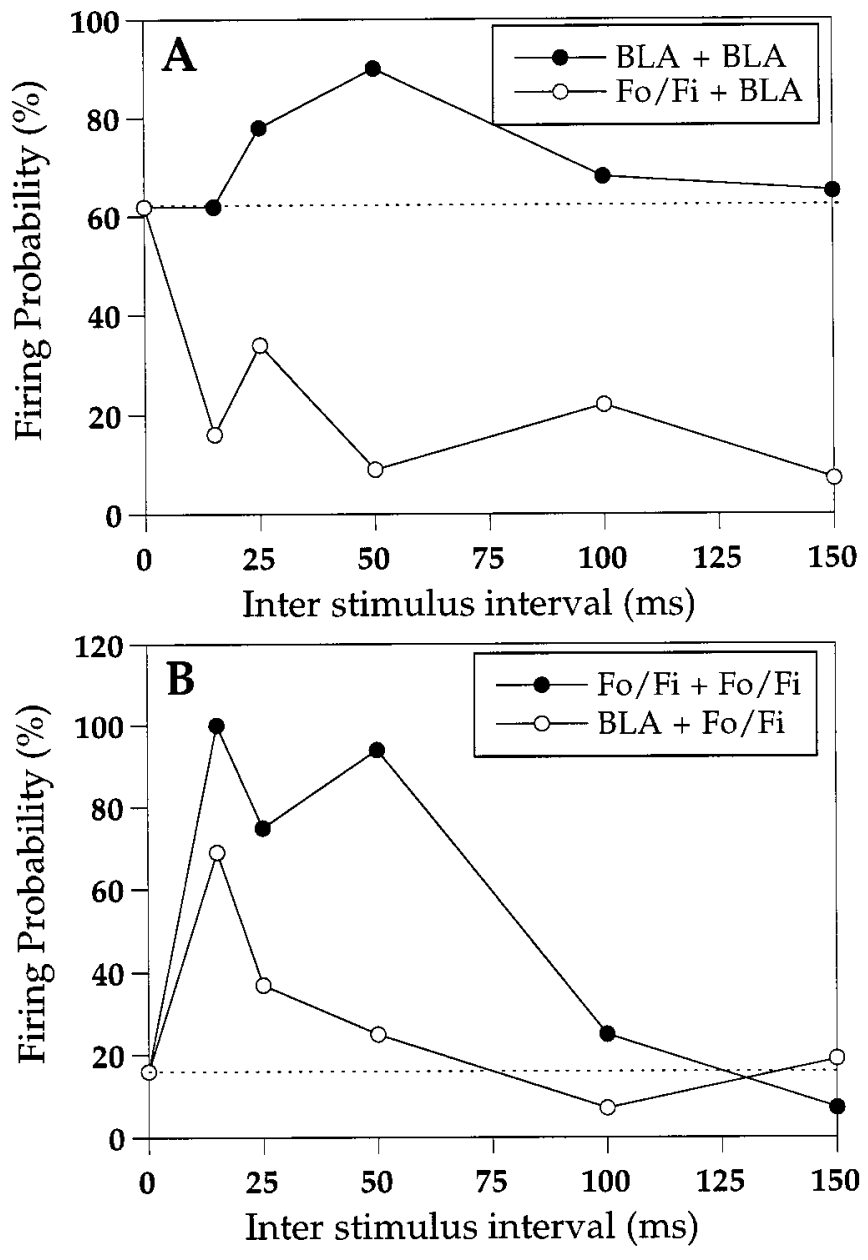

Figure 4. Examples of paired-pulse interactions of the BLA to Nacb and the $\mathrm{Fo} / \mathrm{Fi}$ to Nacb pathways. Paired-pulse stimulation of the BLA results in paired-pulse facilitation $(A)$. However, when the conditioning pulse is applied to the Fo/Fi fibers and the test pulse is applied in the BLA, the latter is strongly attenuated $(A)$ compared with a single BLA conditioning pulse with the same intensity. Double-pulse stimulation of the $\mathrm{Fo} / \mathrm{Fi}$ also results in PPF $(B)$. When the conditioning pulse is applied in the BLA followed by the test pulse in the $\mathrm{Fo} / \mathrm{Fi}$, the latter response is enhanced compared with a single Fo/Fi conditioning pulse with the same intensity. The dashed lines represent the firing probabilities for the conditioning pulses in these experiments.

Table 2. Firing probability of Nacb single units $(n=10)$ to either BLA or $\mathrm{Fo} / \mathrm{Fi}$ stimulation or combinations of $\mathrm{BLA}$ and $\mathrm{Fo} / \mathrm{Fi}$

\begin{tabular}{llll} 
& $\begin{array}{l}\text { Single } \\
\text { BLA }\end{array}$ & $\begin{array}{l}\text { Paired } \\
\text { BLA }+ \text { BLA }\end{array}$ & $\begin{array}{l}\text { Paired } \\
\text { Fo/Fi }+ \text { BLA }\end{array}$ \\
\hline Firing probability & $58 \pm 5 \%$ & $76 \pm 5 \%^{* *}$ & $34 \pm 5 \%^{* *}$ \\
& & Paired & Paired \\
& Single Fo/Fi & Fo/Fi $+\mathrm{Fo} / \mathrm{Fi}$ & $\mathrm{BLA}+\mathrm{Fo} / \mathrm{Fi}$ \\
Firing probability & $48 \pm 6 \%$ & $86 \pm 4 \%^{* * *}$ & $73 \pm 5 \%^{* *}$ \\
\hline
\end{tabular}

On paired stimulation, the value of the test response is presented. Paired-pulse interval is $50 \mathrm{msec}$. Test response in paired stimulations is compared with single response.

two-thirds of the magnocellular basal amygdaloid nucleus reach the Nacb directly via the external capsule to the ventrolateral shell and core, whereas all other areas (including the rostral amygdalar accessory basal and parvicellular basal nuclei) project

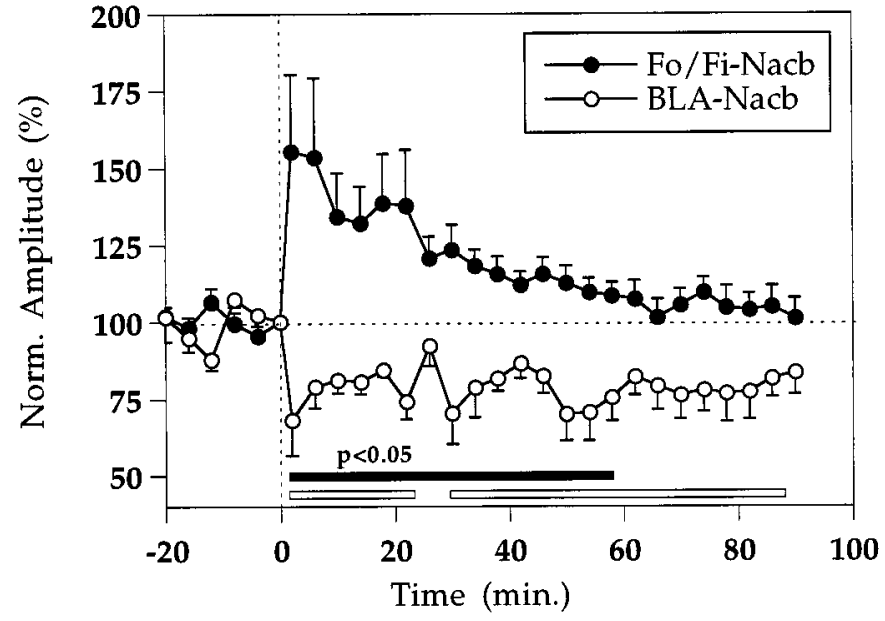

Figure 5. Long-term interaction between the $\mathrm{Fo} / \mathrm{Fi}$ and the BLA to $\mathrm{Nacb}$ pathways after tetanization of the former. LTP in the $\mathrm{Fo} / \mathrm{Fi}$ to $\mathrm{Nacb}$ pathway is presented after a classic tetanus $(50 \mathrm{~Hz}, 2 \mathrm{sec})$. The tetanic stimulation was given at $t=0$. The LTP shows the characteristic initial increase followed by the decremental phase reaching baseline within 60 min as described previously (Boeijinga et al., 1993; Mulder et al., 1993, 1997). The nontetanized BLA to Nacb pathway is depressed (LTD) significantly for $90 \mathrm{~min}$. The bars at the bottom of the graph indicate the level of significance for the post-tetanic values compared with the pretetanic controls. Closed bar, Fo/Fi to Nacb; open bar, BLA to Nacb.

via the stria terminalis to medial parts of the Nacb (Kita and Kitai, 1990; Shinonaga et al., 1994; Wright et al., 1996). Thus, it is likely that these two routes have different conduction times. In addition, the different peak latencies found in shell/core neurons (15 and $19 \mathrm{msec}$ ) could be attributable to the fact that the stria terminalis contains slow as well as fast conducting fibers (Fernandez de Molina and Garcia-Sanchez, 1967).

Both hippocampal and amygdaloid terminals in the Nacb make asymmetrical synapses, primarily on dendritic spines (Totterdell and Smith, 1989; Kita and Kitai, 1990; Meredith et al., 1993; Johnson et al., 1994). An examination of the typical polarity of the field generated by EPSPs in the Nacb, i.e., positive after Fo/Fi stimulation and negative after BLA stimulation, and the coincidence of unit firing with these fields allow us to make some suggestions about the possible distribution of synaptic inputs. Although Nacb field potentials on Fo/Fi stimulation are characterized by a positive deflection (Boeijinga et al., 1993; Mulder et al., 1997), BLA stimulation yields negative field potentials. The finding that through the entire Nacb similar EFPs were recorded, with polarity changes only at the dorsal and ventral borders (Lopes da Silva et al., 1984; Mulder et al., 1997), is in line with the fact that the medium-sized spiny Nacb neurons do not form well defined layers but have cell bodies occupying a central position surrounded by dendrites in all directions (DeFrance et al., 1985; Pennartz and Kitai, 1991; Arts and Groenewegen, 1992). In general terms, extracellular fields are generated by a combination of sinks, at the site of active excitatory synaptic contacts, and sources at the remaining part of the somadendritic membrane (Lopes da Silva, 1996). Therefore, we hypothesize that the hippocampal afferents terminate on distal parts of the dendritic tree of Nacb neurons, forming a distal sink that surrounds the cell body as a narrow ring, whereas the main part of the cell, i.e., the soma and the proximal dendrites, behaves as an extended source. Because these neurons overlap, the resultant field will be dominated by these sources. The finding of negative population spikes 
riding the positive peak of the local field potential strengthens this interpretation. However, after stimulation of the BLA, negative population spikes are found to ride local negative field potential components. Accordingly, we assume that BLA excitatory inputs result in proximal current sinks distributed around the soma and along large areas of the proximal dendrites. Thus we may hypothesize that the hippocampal inputs make synaptic contacts primarily with distal dendrites, whereas the amygdalar synapses are located proximally.

\section{Paired-pulse interactions of amygdalar and hippocampal inputs}

$\mathrm{Fo} / \mathrm{Fi}$ stimulation leads to depression of spontaneous activity of long duration after an initial excitatory response in the Nacb (Mulder et al., 1997). This inhibitory response is likely mediated by GABA-B receptors (Gigg et al., 1994; Finch et al., 1995). If the test stimulus applied to the BLA arrives during this inhibitory period, as in our experiments, the response would be attenuated. In contrast, the homosynaptic paired stimulation of the same Fo/Fi input causes facilitation. The latter is most likely modulated by a strong presynaptic facilitatory mechanism (Kuhnt and Voronin, 1994) that seems to be able to mask the inhibitory component.

The mechanism of the facilitatory heterosynaptic effect of a conditioning BLA input on the test hippocampal response may be accounted for by the fact that BLA inputs, acting on the proximal part of the somadendritic membrane of the stellate spiny neurons of the Nacb, depolarize the latter. Accordingly, the hippocampal inputs that follow a BLA stimulus encounter the soma of the Nacb neurons already in a depolarized state. This could account for a postsynaptic facilitation of this form of paired responses.

\section{Decremental long-term potentiation accompanied by heterosynaptic long-term depression}

Decremental LTP in the Nacb after Fo/Fi tetanization has already been described by us (Boeijinga et al., 1993; Mulder et al., 1993, 1997). The novel finding reported here is that, simultaneously with this form of LTP, a heterosynaptic LTD was encountered in the BLA responses. This heterosynaptic depression could be attributable to the fact that potentiation of the population of cells driven by $\mathrm{Fo} / \mathrm{Fi}$ may cause a potentiation of GABAergic inhibition in surrounding cells. Indeed we found that this form of LTP is accompanied by strong GABAergic feedforward inhibition in this neuronal population (Mulder et al., 1995b). This is compatible with an interpretation that intermingled neuronal populations may respond preferentially to Fo/Fi or to BLA inputs; however, convergence of hippocampal and BLA inputs cannot be ruled out. The heterosynaptic LTD may result from a postsynaptic mechanism (Abraham and Goddard, 1983) that may depress the activity of synapses of a separate input lying in close proximity to the tetanized one.

\section{Functional implications}

Finally, we put forward the hypothesis that the activity of the Fo/Fi to Nacb pathway could result in a "closed gate" with respect to subsequent BLA to Nacb inputs, such as would correspond to a state in which GABAergic activity in the Nacb is at a high level. In contrast, BLA inputs would lead to a state of "open gate"; i.e., they would be permissive, leading to a state of relatively low GABAergic activity. O'Donnell and Grace (1995), using intracellular recordings, consider that the hippocampus appears to gate prefrontal cortico-accumbens throughout. However, such gating mechanisms are likely to depend not only on the nature of the changes of membrane voltage at the soma, but also on the changes in the dendrites. Taking into consideration the distributed synaptic inputs along the extensive dendritic trees of the stellate cells, it would be useful to combine intracellular and extracellular recordings to obtain a more comprehensive idea about how these different types of dynamic "gating" effects take place.

It is relevant to note that the region of the Nacb where the most clear interactions between hippocampal and amygdalar inputs were found correspond closely to areas that have as output targets brainstem structures such as the midbrain extrapyramidal area, the periaqueductal gray, the ventral tegmental area, and the dopaminergic substantia nigra pars compacta (Wright et al., 1996). Therefore this type of interaction between hippocampal and amygdalar inputs in the Nacb, well placed to influence reward and incentive systems, could play a role in behaviors such as conditioned place preference in which place learning, probably mediated by the hippocampal system, depends on the presence of reward, which is mediated by the amygdalar system.

\section{REFERENCES}

Abraham WC, Goddard GV (1983) Asymmetric relationships between homosynaptic long-term potentiation and heterosynaptic long-term depression. Nature 305:717-719.

Adolphs R, Tranel D, Damasio H, Damasio AR (1995) Fear and the human amygdala. J Neurosci 15:5879-5891.

Alvarez P, Zola-Morgan S, Squire LR (1995) Damage to the hippocampal region produces long-lasting memory impairment in monkeys. J Neurosci 15:3796-3807.

Arts MPM, Groenewegen HJ (1992) Relationships of the dendritic arborations of ventral striatomesencephalic projection neurons with boundaries of striatal compartments. An in vitro intracellular labelling study in the rat. Eur J Neurosci 4:574-588.

Berendse HW, Groenewegen HJ, Lohman AHM (1992) Compartmental distribution of ventral striatal neurons projecting to the mesencephalon in the rat. J Neurosci 12:2079-2103.

Boeijinga PH, Pennartz CMA, Lopes da Silva FH (1990) Paired-pulse facilitation in the nucleus accumbens following stimulation of the subicular inputs in the rat. Neuroscience 35:301-311.

Boeijinga PH, Mulder AB, Pennartz CMA, Manshanden I, Lopes da Silva FH (1993) Response of the nucleus accumbens following fornix/ fimbria stimulation of the rat. Identification and long-term potentiation of mono- and polysynaptic pathways. Neuroscience 53:1049-1058.

Calloway C, Hakan RL, Henriksen SJ (1991) Distribution of amygdala input to the nucleus septi: an electrophysiological investigation. J Neural Transmembr 83:215-225.

Christie MJ, Summers RJ, Stephenson JA, Cook CJ, Beart PM (1987) Excitatory amino acid projections to the nucleus accumbens septi in the rat: A retrograde transport study utilizing $\mathrm{d}\left[{ }^{3} \mathrm{H}\right]$ aspartate and $\left[{ }^{3} \mathrm{H}\right]$ GABA. Neuroscience 22:425-439.

Davies M (1992) The role of the amygdala in conditioned fear. In: The amygdala, neurobiological aspects of emotion, memory, and mental dysfunction (Aggleton JP, ed), pp 255-305. New York: Wiley.

DeFrance JF, Marchand J, Stanley JC, Sikes RW, Chronister RB (1980) Convergence of excitatory amygdaloid and hippocampal input in the nucleus accumbens septi. Brain Res 185:183-186.

DeFrance JF, Marchand JF, Sikes RW, Chronister RB, Hubbard JI (1985) Characterization of fimbria input to nucleus accumbens. J Neurophysiol 54:1553-1567.

Fernandez de Molina A, Garcia-Sanchez JL (1967) The properties of the stria terminalis fibers. Physiol Behav 2:225-227.

Finch DM (1996) Neurophysiology of converging synaptic inputs from rat prefrontal cortex, amygdala, midline thalamus, and hippocampal formation onto single neurons of the caudate/putamen and nucleus accumbens. Hippocampus 6:495-512.

Finch DM, Gigg J, Tan AM, Kosoyan OP (1995) Neurophysiology and neuropharmacology of projections from entorhinal cortex to striatum in the rat. Brain Res 670:233-247.

Gigg J, Tan AM, Finch DM (1994) Glutamatergic hippocampal formation projections to prefrontal cortex in the rat are regulated by GABAergic inhibition and show convergence with glutamatergic projections from the limbic thalamus. Hippocampus 4:189-198. 
Groenewegen HJ, Vermeulen-Van Der Zee E, te Kortschot A, Witter MP (1987) Organization of the projections from the subiculum to the ventral striatum in the rat. A study using anterograde transport of phaseolus vulgaris leucoagglutinin. Neuroscience 23:103-120.

Heimer L, Wilson RD (1975) The subcortical projections of the allocortex: similarities in the neural associations of the hippocampus, the piriform cortex, and the neocortex. In: Perspectives in neurobiology. Golgi centennial symposium (Santini M, ed), pp 177-193. New York: Raven.

Heimer L, Zahm DS, Churchill L, Kalivas PW, Wohltmann C (1991) Specificity in the projection patterns of the accumbal core and shell in the rat. Neuroscience 41:89-125.

Johnson LR, Aylward RL, Hussain Z, Totterdell S (1994) Input from the amygdala to the rat nucleus accumbens: its relationship with tyrosine hydroxylase immunoreactivity and identified neurons. Neuroscience 61:851-865.

Jongen-Rêlo A, Voorn P, Groenewegen HJ (1994) Immunohistochemical characterization of the shell and core territories of the nucleus accumbens in the rat. Eur J Neurosci 6:1255-1264.

Kirouac GJ, Ganguly PK (1995) Topographical organization in the nucleus accumbens of afferents from the basolateral amygdala and efferents to the lateral hypothalamus. Neuroscience 67:625-630.

Kita H, Kitai ST (1990) Amygdaloid projections to the frontal cortex and the striatum in the rat. J Comp Neurol 298:40-49.

Krettek JE, Price JL (1978) Amygdaloid projections to subcortical structures within the basal forebrain and brainstem in the rat and cat. J Comp Neurol 178:225-254.

Kuhnt U, Voronin LL (1994) Interaction between paired pulse facilitation and long-term potentiation in area CA1 of guinea-pig hippocampal slices: application of quantal analysis. Neuroscience 62:391-397.

Laroche S, Jay TM, Thierry AM (1990) Long-term potentiation in the prefrontal cortex following stimulation of the hippocampal CA1/subicular region. Neurosci Lett 114:184-190.

LeDoux JE (1993) Emotional memory systems in the brain. Behav Brain Res 58:69-79.

Lopes da Silva FH (1996) The generation of electric and magnetic signals of the brain by local networks. In: Comprehensive human physiology, Vol 1 (Gregor R, Windhorst U, eds), pp 509-531. Berlin: Springer.

Lopes da Silva FH, Arnold DEAT, Neijt HC (1984) A functional link between the limbic cortex and ventral striatum: physiology of the subiculum-accumbens pathway. Exp Brain Res 55:205-214.

McDonald AJ (1991) Topographical organization of amygdaloid projections to the caudatoputamen, nucleus accumbens, and related striatallike areas of the rat brain. Neuroscience 44:15-33.

Meredith GE, Pennartz CMA, Groenewegen HJ (1993) The cellular framework for chemical signalling in the nucleus accumbens. Prog Brain Res 99:3-24.

Mogenson GJ, Nielsen M (1984) A study of the contribution of hippocampal-accumbens-subpallidal projections to locomotor activity. Behav Neural Biol 42:38-51.

Mogenson GJ, Jones DL, Yim CY (1980) From motivation to action: functional interface between the limbic system and the motor system. Prog Neurobiol 14:69-97.

Morris RGM, Garrud P, Rawlins JNP, O'Keefe J (1982) Place navigation impaired in rats with hippocampal lesions. Nature 297:681-683.

Mulder AB, Lopes da Silva FH (1996) Interaction of the hippocampus and the basolateral amygdala inputs to the nucleus accumbens. Soc Neurosci Abstr 22:911.

Mulder AB, Arts MPM, Lopes da Silva FH (1993) Long term potentiation simultaneously induced in nucleus accumbens, prefrontal cortex, and hippocampus. Neurosci Res Commun 13:11-14.

Mulder AB, Gijsberti Hodenpijl M, Lopes da Silva FH (1995a) Electrophysiology of the hippocampal and basolateral amygdaloid inputs to the nucleus accumbens of the rat: patterns of convergence and segregation. Eur J Neurosci [Suppl] 8:151.
Mulder AB, Zuiderwijk M, Lopes da Silva FH (1995b) Enhancement of long-term potentiation in the nucleus accumbens by removal of GABAergic inhibition. Pflügers Arch 430:R177.

Mulder AB, Arts MPM, Lopes da Silva FH (1997) Short- and long-term plasticity of the hippocampus to nucleus accumbens and prefrontal cortex pathways in the rat, in vivo. Eur J Neurosci 9:1603-1611.

Napier TC, Mitrovic I, Churchill L, Klitenick MA, Lu XY, Kalivas PW (1995) Substance P in the ventral pallidum: projection from the ventral striatum, and electrophysiological and behavioral consequences of pallidal substance P. Neuroscience 69:59-70.

Nauta WJH, Smith GP, Faull RL, Domesick VB (1978) Efferent connections and nigral afferents of the nucleus accumbens in the rat. Neuroscience 3:385-401.

O’Donnell P, Grace AA (1995) Synaptic interactions among excitatory afferents to nucleus accumbens neurons: hippocampal gating of prefrontal cortical input. J Neurosci 15:3622-3639.

Paxinos G, Watson C (1996) The rat brain in stereotaxic coordinates. New York: Academic.

Pellegrino LJ, Pellegrino AS, Cushman AJ (1981) A stereotaxic atlas of the rat brain, Ed 2. New York: Plenum.

Pennartz CMA, Kitai ST (1991) Hippocampal inputs to identified neurons in an in vitro slice preparation of the rat nucleus accumbens: evidence for feed-forward inhibition. J Neurosci 11:2838-2847.

Shinonaga Y, Takada M, Mizuno N (1994) Topographic organization of collateral projections from the basolateral amygdaloid nucleus to both the prefrontal cortex and the nucleus accumbens in the rat. Neuroscience 58:389-397.

Totterdell S, Smith AD (1989) Convergence of hippocampal and dopaminergic input onto identified neurons in the nucleus accumbens of the rat. J Chem Neuroanat 2:285-298.

Wright CI, Beijer AVJ, Groenewegen HJ (1996) Basal amygdaloid complex afferents to the rat nucleus accumbens are compartmentally organized. J Neurosci 16:1877-1893.

Yang CR, Mogenson GJ (1984) Electrophysiological responses of neurons in the nucleus accumbens to hippocampal stimulation and the attenuation of the excitatory responses by the mesolimbic dopaminergic system. Brain Res 324:69-84.

Yang CR, Mogenson GJ (1985) An electrophysiological study of the neural projections from the hippocampus to the ventral pallidum and the subpallidal areas by way of the nucleus accumbens. Neuroscience 15:1015-1024.

Yim CY, Mogenson GJ (1982) Response of nucleus accumbens neurons to amygdala stimulation and its modification by dopamine. Brain Res 239:401-415.

Yim CY, Mogenson GJ (1986) Mesolimbic dopamine projection modulates amygdala-evoked EPSP in nucleus accumbens neurons: an in vivo study. Brain Res 369:347-352.

Yim CY, Mogenson GJ (1989) Low doses of nucleus accumbens dopamine modulate amygdala suppression of spontaneous exploratory activity in rats. Brain Res 477:202-210.

Zola-Morgan S, Squire LR, Amaral DG (1986) Human amnesia and the medial temporal region: enduring memory impairment following a bilateral lesion limited to field CA1 of the hippocampus. J Neurosci 6:2950-2967.

Zola-Morgan S, Squire LR, Amaral DG (1989) Lesions of the hippocampal formation but not lesions of the fornix or the mammillary nuclei produce long-lasting memory impairments in monkeys. J Neurosci 9:898-913.

Zola-Morgan S, Squire LR, Alvarez-Royo P, Clower RP (1991) Independence of memory functions and emotional behaviour: separate contributions of the hippocampal formation and the amygdala. Hippocampus 1:207-220. 